\title{
Third trimester Doppler ultrasound as prediction of obstetric outcome in high-risk pregnancy, Gujarat, India
}

\author{
Runoo Ghosh ${ }^{1 *}$, Hina Oza², Shikha Meel $^{2}$ \\ ${ }^{1}$ Department of Obstetrics and Gynecology, GMERS Medical College, Gandhinagar, Gujarat, India \\ ${ }^{2}$ Department of Obstetrics and Gynecology, B J Medical College, Ahmedabad, Gujarat, India
}

Received: 01 June 2017

Accepted: 27 June 2017

*Correspondence:

Dr. Runoo Ghosh,

E-mail: drrunoog@gmail.com

Copyright: $\odot$ the author(s), publisher and licensee Medip Academy. This is an open-access article distributed under the terms of the Creative Commons Attribution Non-Commercial License, which permits unrestricted non-commercial use, distribution, and reproduction in any medium, provided the original work is properly cited.

\section{ABSTRACT}

Background: Doppler ultrasound has emerged as beneficial tool in the assessment of the fetal and placental circulation and in the prediction of adverse pregnancy outcome. Umbilical artery Doppler has proved helpful to supervise the growth restricted fetuses and compromised vasculature as in hypertensive disorders high risk pregnancies. Objective of present study was to investigate the association between third-trimester uterine artery Doppler assessment and adverse obstetric outcome.

Methods: This prospective study was done among 110 high risk pregnancies. Vessel like uterine artery, umbilical artery, middle cerebral artery and ductus venosus were studied in present study. Indices calculated: Peak systolic velocity, End diastolic velocity, Mean velocity, Systolic/diastolic ratio, Pulsatility index (PI) and resistance index (RI) of middle cerebral artery (MCA), Ductus venosus S/A ratio.

Results: bilateral notch was present statistically significant $(p<0.05)$ in $18.1 \%$ and absent in $28.2 \%$ among cases of adverse perinatal outcome. UA S/D ratio was $>3$ in $22.7 \%$ and $<3$ in $11.8 \%$ among cases of adverse perinatal outcome and findings were statistically significant $(\mathrm{p}<0.05)$. End diastolic velocity was reduced in statistically significant $(\mathrm{p}<0.05)$ in $9.1 \%$ and normal in $20.1 \%$ among cases of adverse perinatal outcome. MCA PI was <lower limit statistically significant $(p<0.05)$ in $24.5 \%$ and >lower limit in $18.2 \%$ among cases of adverse perinatal outcome. MCA PI/UA PI ratio was $<1$ statistically significant $(\mathrm{p}<0.05)$ in $25.5 \%$ and absent in $17.3 \%$ among cases of adverse perinatal outcome.

Conclusions: Increase in UA PI and decrease in MCA PI are early marker for detection of fetal compromise. Ratio of indices between MCA PI and UA PI reflects brain sparing effect as well as placental insufficiency and these are more specific in detection of IUGR than individual artery indices.

Keywords: Bilateral diastolic notches, Pre-eclampsia, Perinatal outcome, Uterine artery Doppler

\section{INTRODUCTION}

Doppler ultrasound has emerged as beneficial tool in the assessment of the fetal and placental circulation and in the prediction of adverse pregnancy outcome. ${ }^{1,2}$ Doppler knowledge has been identifying to decrease the figure of emergency operations, hospital admissions, and days in hospital for both mother and newborn in cases of suspected IUGR. ${ }^{3}$ During first and second trimester, an ultrasound examination is used to the fetal malformations and to assess fetal growth disorders. ${ }^{4}$ Almost $4-10 \%$ pregnant women suffered from pre-eclampsia (PE) and intrauterine growth restriction (IUGR) which resulted in maternal morbidity and premature iatrogenic deliveries. Since many years, lots of studies done on Doppler ultrasound have found that increased blood flow resistance in the uterine arteries is associated with increased risk of PE and/or IUGR and other adverse 
perinatal outcomes. ${ }^{5,6}$ Doppler of uteroplacental circulation plays a important part in treatment of highrisk pregnancies. It helps one to determine the fetus at risk and at time of delivery. Umbilical artery Doppler has proved helpful to supervise the growth restricted fetuses and compromised vasculature as in hypertensive disorders high risk pregnancies. However, number of studies proved that uterine artery Doppler useful even in the third trimester to identify adverse perinatal outcome. ${ }^{7,8}$ The aim of present study was to investigate the association between third-trimester uterine artery Doppler assessment and adverse obstetric outcome.

\section{METHODS}

This prospective study was done among 110 high risk pregnancies admitted at department of obstetrics and Gynecology in B.J. Medical college, Ahmedabad during July 2008 to October 2012. Data collection was done after ethical permission from institutional ethical committee and informed consent of clients.

Inclusion criteria for present study was all pregnant women irrespective of age and parity with high risk factors like preeclampsia, oligohydramnions, anemia and renal disease etc.

Exclusion criteria was women with multiple pregnancy, congenital malformation and placenta previa, abruptio placenta etc. Vessel like uterine artery, umbilical artery, middle cerebral artery and ductus venosus were studied in present study. After taking detail history, a thorough clinical examination of the clients was carried out with preliminary investigations like SGPT, SGOT, Serum total protein, S. uric acid and fundoscopy. EDD was calculated from LMP and by USG done in first trimester of pregnancy.

1. Ultrasound scanning: after ensuring single live pregnancy, lie, presentation, gestational age, amount of liquor, placental localization and maturation, any congenital anomalies, presence or absence of IUGR were recorded.

2. Doppler velocimetry: It was done beyond 28 weeks of gestation in all patients, repeated after 2 weeks or earlier if and when required

3. Indices calculated:

- Peak systolic velocity

- End diastolic velocity

- Mean velocity

- Systolic/diastolic ratio

- Pulsatility index (PI) and resistance index (RI) of middle cerebral artery (MCA)

- Ductus venosus S/A ratio

4. Interpretation of Doppler findings

- Uterine artery having bilateral diastolic notches
- Umbilical artery S/D ratio more than 3 or more than 95 percentile of reference value, pulsatality index more than 95 percentile of reference value or if the diastolic flow was absent or reversed

- Middle cerebral artery PI less than lower limit of reference value

- MCA/UA PI ratio less than 1 of reference value

- $\mathrm{MCA} / \mathrm{UA}$ S/D ratio than 1

- DV having absent or reversed flow as seen in ' $a$ ' wave

5. Follow up of patients:

- With normal Doppler follow up till delivery

- With abnormal Doppler weekly or earlier

6. For neonatal information like mode of delivery, indication of caesarean section, APGAR score at 5 and 10 minutes, antepartum/intrapartum sign of fetal distress, birth weight, admission to intensive care unit, any intrauterine death or still birth, gestation age at birth.

\section{RESULTS}

Table 1 shows that mean maternal age was 26.8 years with $5.9 \mathrm{SD}$ and more than $50 \%$ participants belonged to 21 to 25 years age group.

Almost 51.0\% participants were primigravida and 53.6\% birth was done through vaginal route. Fetal distress was the main indication for caesarian section. Mean birth weight was $2150 \mathrm{gm}$ with $256.7 \mathrm{SD}$.

Table 1: Patient characteristics and pregnancy outcome $(\mathrm{N}=110)$.

\begin{tabular}{|ll|}
\hline Parameters & Number $(\%)$ \\
\hline Maternal age $($ Mean \pm SD) & $26.8 \pm 5.9$ \\
\hline Maternal age $(21-25$ years) & $57(51.8 \%)$ \\
\hline Gravidity & \\
\hline Primi & $56(51.0)$ \\
\hline Multi & $54(49.0)$ \\
\hline Mode of delivery & $59(53.6)$ \\
\hline Vaginal & $51(46.4)$ \\
\hline Caesarean & \\
\hline Indication for caesarean section & $33(60.0)$ \\
\hline Fetal distress & $5(9.1)$ \\
\hline Severe pre-eclampsia & $17(30.9)$ \\
\hline Other & \\
\hline Birth weight (gm) & $51(46.4)$ \\
\hline$<2500$ & $57(51.8)$ \\
\hline $2500-4000$ & $2(1.8)$ \\
\hline$>4000$ & $2150 \pm 256.7$ \\
\hline $\begin{array}{l}\text { Mean birth weight }(\mathrm{gm}) \\
\text { (Mean } \pm \text { SD) }\end{array}$ & \\
\hline
\end{tabular}

Table 2: Distribution of cases in relation to pregnancy complication. 


\begin{tabular}{|ll|}
\hline Pregnancy complication & Number $(\%)$ \\
\hline Oligohydramnios & $60(54.5)$ \\
\hline SFGR & $53(48.2)$ \\
\hline Pre-eclamsia & $36(32.7)$ \\
\hline Anemia & $21(19.1)$ \\
\hline PIH+Oligo & $11(10.0)$ \\
\hline Post-dated pregnancy & $6(5.5)$ \\
\hline PIH+Anemia & $6(5.5)$ \\
\hline Cardiac disease & $3(2.7)$ \\
\hline Anemia+Oligo & $2(1.8)$ \\
\hline Bad obstetric history & $2(1.8)$ \\
\hline Renal disease & $1(0.9)$ \\
\hline Liver disease & $1(0.9)$ \\
\hline
\end{tabular}

Table 2 shows that Oligohydramnios, SFGR, Preeclamsia, Anemia are the most common pregnancy complications respectively.

Table 3: Association of Doppler ultrasound findings with perinatal outcome $(\mathrm{N}=110)$.

\begin{tabular}{|c|c|c|c|}
\hline \multirow{2}{*}{$\begin{array}{l}\text { Doppler } \\
\text { ultrasound } \\
\text { findings }\end{array}$} & \multicolumn{2}{|c|}{ Perinatal outcome } & \multirow[b]{2}{*}{ p value } \\
\hline & Adverse & Normal & \\
\hline \multicolumn{3}{|c|}{ Bilateral notch } & \multirow{3}{*}{0.004} \\
\hline Present & $20(18.1)$ & $8(7.3)$ & \\
\hline Absent & $31(28.2)$ & $51(46.4)$ & \\
\hline \multicolumn{3}{|c|}{ UA S/D ratio } & \multirow{3}{*}{0.0001} \\
\hline$>3$ & $25(22.7)$ & $13(11.8)$ & \\
\hline$<3$ & $13(11.8)$ & $59(53.7)$ & \\
\hline \multicolumn{3}{|c|}{ End Diastolic velocity } & \multirow{5}{*}{0.0001} \\
\hline Reduced & $10(9.1)$ & $6(5.5)$ & \\
\hline AEDF & $8(7.3)$ & $0(0.0)$ & \\
\hline REDF & $9(8.2)$ & $0(0.0)$ & \\
\hline Normal & $23(20.1)$ & $54(49.1)$ & \\
\hline \multicolumn{3}{|l|}{ MCA PI } & \multirow{3}{*}{0.0003} \\
\hline$<$ lower limit & $27(24.5)$ & $14(12.3)$ & \\
\hline >lower limit & $20(18.2)$ & $49(44.5)$ & \\
\hline \multicolumn{3}{|c|}{ MCA PI/UA PI ratio } & \multirow{3}{*}{0.0001} \\
\hline$<1$ & $28(25.5)$ & $5(4.5)$ & \\
\hline$>1$ & $19(17.3)$ & $58(52.7)$ & \\
\hline
\end{tabular}

Table 3 shows that bilateral notch was present statistically significant $(\mathrm{p}<0.05)$ in $18.1 \%$ and absent in $28.2 \%$ among cases of adverse perinatal outcome. UA $\mathrm{S} / \mathrm{D}$ ratio was $>3$ in $22.7 \%$ and $<3$ in $11.8 \%$ among cases of adverse perinatal outcome and findings were statistically significant $(\mathrm{p}<0.05)$.

End diastolic velocity was reduced in statistically significant $(\mathrm{p}<0.05)$ in $9.1 \%$ and normal in $20.1 \%$ among cases of adverse perinatal outcome. MCA PI was <lower limit statistically significant $(\mathrm{p}<0.05)$ in $24.5 \%$ and $>$ lower limit in $18.2 \%$ among cases of adverse perinatal outcome. MCA PI/UA PI ratio was $<1$ statistically significant $(\mathrm{p}<0.05)$ in $25.5 \%$ and absent in $17.3 \%$ among cases of adverse perinatal outcome.

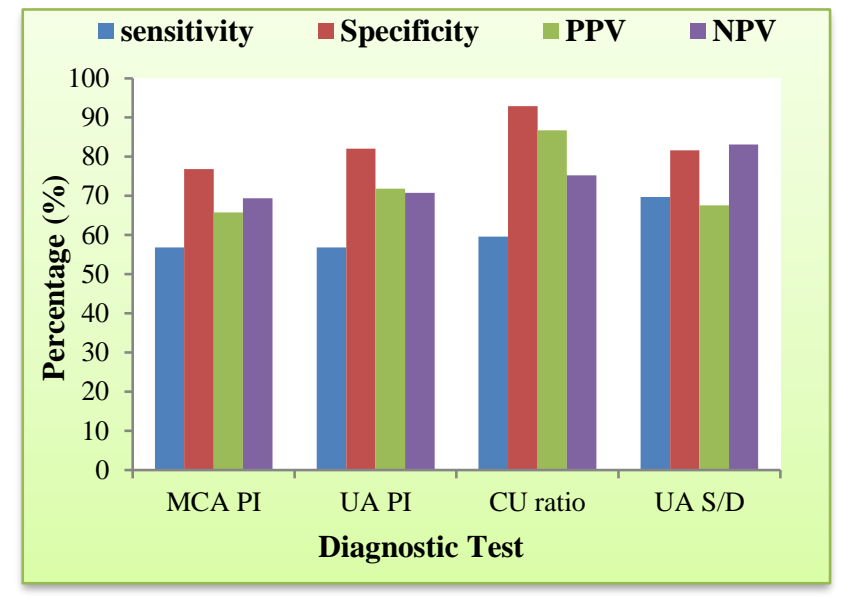

Figure 1: Comparison of standard diagnostic test in prediction of abnormal perinatal outcome

Figure 1 shows that abnormal perinatal outcome correctly found in $56.8 \%, 56.8 \%, 59.6 \%$ and $68.7 \%$ cases by MCA PI, UA PI, CU ratio and UA S/D ratio test respectively. Specificity to find abnormal perinatal outcome was $76.8 \%, 82.1 \%, 92.9 \%$ and $81.6 \%$ cases by MCA PI, UA $\mathrm{PI}, \mathrm{CU}$ ratio and UA S/D ratio test respectively.

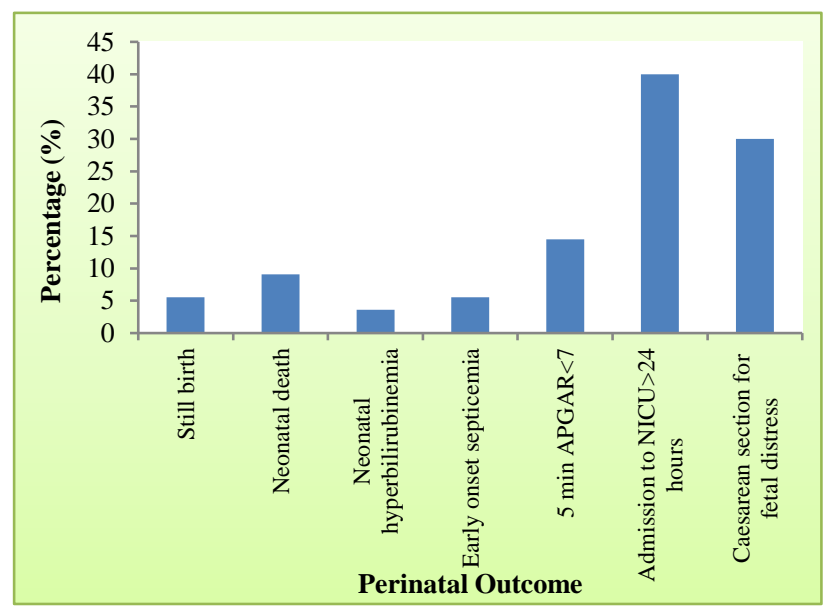

Figure 2: Perinatal outcome among study participants

Figure 2 shows that most common adverse perinatal outcome was admission in NICU >24 hours, fetal distress, APGAR score <7, Neonatal death respectively.

Abnormal ductus venosus was found abnormal flow pattern in 6 cases and all these 6 cases have adverse perinatal outcome was observed.

\section{DISCUSSION}

The relation between adverse perinatal outcome and intrauterine growth restriction, oligohydramnios and adverse outcome is well known and lots of research found that uterine artery Doppler very useful in the prediction of uteroplacental insufficiency from early and late gestation. ${ }^{9,10}$ 
Mean maternal age in present study was 26.8 years and these findings are consistent with the similar study done by wald RM et al, Garcia et al and Rai L et al. ${ }^{11-13}$ Study included similar number of participants of primigravida and multigravida. Caesarean section was reportedly less in number in comparison with vaginal delivery and fetal distress eas the main indication for caesarean section. These findings are comparable with the findings of study done by Rai L et al and Garcia B et al. ${ }^{12,13}$ Mean birth weight in present study was 2150 gm but these findings are not comparable with similar study done by Wald RM et al, Garcia B at al, Peixoto et al and Li H et al. ${ }^{6,11,12,14}$ Oligohydramnios, SFGR, Pre-eclamsia, Anemia are the most common pregnancy complications respectively.

Ultrasound doppler screening is the relatively low detection rate, especially for late-onset cases during second trimester of pregnancy. ${ }^{12}$ Present study found statistically significant association between adverse perinatal outcome with presence of bilateral notch in uterine artery doppler, UA S/D ratio, end diastolic velocity, MCA PI and MCA PI/UA PI ratio. Hofstaetter et al reported uterine artery notch to be a better predictor of perinatal outcome than unilateral high PI. ${ }^{15}$ This is in contrast to the findings of Ghosh et al where RI and PI were considered better indicators of vascular impedance in predicting adverse perinatal outcomes. ${ }^{16}$

$\mathrm{B} / \mathrm{L}$ notch in uterine artery Doppler was present in $25.4 \%$ participants and this findings are quit comparable with the similar study done by Wald RM et al, Rai L et al but not consistent with study done by Maria AL et al and Li $\mathrm{H}$ et al. ${ }^{11,13,14,17}$ Study found acceptable sensitivity, specificity, PPV and NPV of Doppler ultrasound during third trimester to predict obstetrical and perinatal outcome and this findings are comparable with study done by Rai L et al. ${ }^{13}$

Limitations of this study was number of cases has been small and study not included Patients who came in labor or with a complication like abruptio placenta.

\section{CONCLUSION}

The use of Doppler ultrasound in high risk pregnancies appears to improve a number of obstetric care outcomes and appear promising in helping to reducing perinatal deaths. Increase in UA PI and decrease in MCA PI are early marker for detection of fetal compromise. Ratio of indices between MCA PI and UA PI reflects brain sparing effect as well as placental insufficiency and these are more specific in detection of IUGR than individual artery indices.

Funding: No funding sources Conflict of interest: None declared

Ethical approval: The study was approved by the Institutional Ethics Committee

\section{REFERENCES}

1. Gudmundsson S, Marsal K. Blood velocity waveforms in the fetal aorta and umbilical artery as predictors of fetal outcome. Am J Perinatol. 1991;8:1-6.

2. Gudmundsson S, Korszun P, Olofsson P, Dubiel M. A new score indicating placental vascular resistance. Acta Obstet Gynecol Scand. 2003;82:807-12.

3. Almstrom H, Axelsson O, Cnattingius S, Ekman G, Maesel A, Ulmsten $U$ et al. Comparison of umbilical-artery velocimetry and cardiotocography for surveillance of small-for-gestational-age fetuses. Lancet. 1992;340:936-40.

4. Mandruzzato G, Meir YJ, Natale R, Maso G. Antepartal assessment of IUGR fetuses. J Perinat Med. 2001;29:222-3.

5. Hauth JC, Ewell MG, Levine RJ, Esterlitz JR, Sibai B, Curet LB et al. Pregnancy outcomes in the healthy nulliparas who developed hypertension. Calcium for Preeclampsia Prevention Study Group. Obstet Gynecol. 2000;95:24-8.

6. Alberto BP, Taciana MR, Tacito AGS, Mario SSG, Wellington PM, Eduardo FMS et al. Assessment of ultrasound and Doppler parameters in the third trimester of pregnancy as predictors of adverse perinatal outcome in unselected pregnancies. Ginekologia Polska. 2016;87(7):510-5.

7. Sekizuka N, Hasegawa I, Takakuwa K, Tanaka K. Scoring of uterine artery flow velocity waveform in the assessment of fetal growth restriction and/or pregnancy induced hypertension. J Matern Fetal Invest. 1997; 7:197-200.

8. Hernandez-Andrade E, Brodszki J, Lingman G, Gudmundsson S, Molin J, Marsal K. Uterine artery score and perinatal outcome. Ultrasound Obstet Gynecol. 2002; 19:438-42.

9. Manning FA, Morrison I, Harman CR, Lange IR, Mentiglou S. Fetal assessment based on the fetal biophysical profile scoring: experience in 19221 referred high-risk pregnancies. II. An analysis of falsenegative fetal deaths. Am J Obstet Gynecol. 1987;157:880-4.

10. Harrington K, Cooper D, Lees C, Hecher K, Campbell S. Doppler ultrasound of the uterine arteries: the importance of bilateral notching in the prediction of pre-eclampsia, placental abruption, or delivery of a small-for-gestational age baby. Ultrasound Obstet Gynecol. 1996;7:182-8.

11. Wald RM, Candice KS, John K, Toi A, Lau CS, Mason J. Maternal Cardiac Output and Fetal Doppler Predict Adverse Neonatal Outcomes in Pregnant Women With Heart Disease. J Am Heart Assoc. 2015;4:1-11.

12. Garcia B, Llubra E, Valle L, Gomez R, Juan M, Perezmatos C. Do knowledge of uterine artery resistance in the second trimester a nd targeted surveillance improve maternal and perinatal outcome? UTOPIA study: a randomized controlled trial. Ultrasound Obstet Gynecol. 2016;47:680-9. 
13. Rai L, Lekshmi S. Value of third trimester uterine artery doppler in high-risk pregnancies for prediction of adverse perinatal outcome. South Asian Federation of Obstet Gynecol. 2010;2(1):31-5.

14. Li H, Gudnason H, Olofsson P, Dubiel M, Gudmundsson S. Increased uterine artery vascular impedance is related to adverse outcome of pregnancy but is present in only one-third of late third-trimester pre-eclamptic women. Ultrasound Obstet Gynecol. 2005;25:459-63.

15. Hofstaetter C, Dubiel M, Gudmundsson S, Marsal K. Uterine artery color Doppler assisted velocimetry and perinatal outcome. Acta Obstet Gynecol Scand. 1996;75:612-9.

16. Ghosh G, Breborowicz A, Brazert M, Maczkiewicz M, Kobelski M, Dubiel M et al. Evaluation of third trimester uterine artery flow velocity indices in relationship to perinatal complications. J Mat-Fetal Neonat Med. 2006;19:551-5.

17. Lopez-Mendez MA, Martinez-Gaytan V, CortesFlores R, Ramos-Gonzalez RM, Ochoa-Torres MA, Garza-Veloz I et al. Doppler ultrasound evaluation in preeclampsia. BMC Res Notes. 2013;6:477.

Cite this article as: Ghosh $\mathrm{R}$, Oza $\mathrm{H}$, Meel S. Third trimester Doppler ultrasound as prediction of obstetric outcome in high-risk pregnancy, Gujarat, India. Int J Reprod Contracept Obstet Gynecol 2017;6:3518-22. 